\title{
Qualitative study of physician perspectives on classifying screening and nonscreening colonoscopy using administrative health data: Adding practice does not make perfect
}

\author{
Maida J Sewitch $\mathrm{PhD}^{1}$, Robert Hilsden $\mathrm{MD} \mathrm{PhD}^{2}$, Lawrence Joseph $\mathrm{PhD}^{1}$, \\ Linda Rabeneck MD MPH${ }^{3}$, Lawrence Paszat MD MSc${ }^{4}$, Alain Bitton MD ${ }^{1}$, Mary Anne Cooper $\mathrm{MD}^{4}$
}

\begin{abstract}
MJ Sewitch, R Hilsden, L Joseph, et al. Qualitative study of physician perspectives on classifying screening and nonscreening colonoscopy using administrative health data: Adding practice does not make perfect. Can J Gastroenterol 2012;26(12):889-893.
\end{abstract}

BACKGROUND: Previously developed screening colonoscopy algorithms based on diagnostic and endoscopy procedural variables have not been sufficiently accurate for use in epidemiological and health services research.

OBJECTIVE: To increase understanding of the administrative health database variables that could help to discern screening and nonscreening colonoscopy.

METHODS: A qualitative study using physician focus groups was conducted in Montreal (Quebec), Calgary (Alberta) and Toronto (Ontario). Specialty-specific focus group sessions were held among family physicians and gastroenterologists - the physicians responsible for referring patients to and performing screening colonoscopy, respectively. Interview guides were developed to better understand physician clinical and billing practices. Discussions were audiotaped, transcribed verbatim and analyzed using the constant comparative approach.

RESULTS: Forty family physicians and seven gastroenterologists participated in five focus group sessions. Patient variables included demographics (age) and medical history (colorectal cancer risk factors/ symptoms, medication for colorectal cancer risk factors/symptoms, gastrointestinal disorders, severe disease). Clinical practice variables included timing of the colonoscopy (evenings, weekends, holidays, during hospitalization; same-day endoscopist consultation and colonoscopy), use of services (hospitalization, annual examination, transfer from other facility) and procedure use patterns (large bowel or other medical/surgical procedure before and subsequent to colonoscopy). However, wide variability in clinical and billing practices will likely preclude the development of a reasonably accurate screening colonoscopy algorithm. Physicians suggested adding a screening colonoscopy code to the administrative health data.

CONCLUSIONS: Failure to acknowledge the limitations of the provincial administrative health databases to identify screening colonoscopy may lead to incorrect conclusions and the establishment of inappropriate health care policies.

Key Words: Colonoscopy indication; Colorectal cancer screening; Physician perspective; Qualitative

Colonoscopy is central to any colorectal cancer (CRC) screening strategy as either the initial screening examination or the followup to positive results of a fecal occult blood test (FOBT), fecal immunochemical test, flexible sigmoidoscopy and double-contrast barium enema (1). With the recent launches of population-based screening programs (2), administrative health databases may be used
Une étude qualitative des points de vue des médecins sur la classification des coloscopies de dépistage et non liées au dépistage au moyen de données administratives sur la santé : à force de forger, on ne devient pas toujours forgeron

HISTORIQUE : Les algorithmes de coloscopie de dépistage déjà existants, fondés sur le diagnostic et les variables de l'endoscopie, ne sont pas assez précis pour être utilisés en recherche épidémiologique et en recherche sur les services de santé.

OBJECTIF : Mieux comprendre les variables des bases de données administratives sur la santé susceptibles de contribuer à discerner la coloscopie de dépistage de la coloscopie non liée au dépistage.

MÉTHODOLOGIE : Les chercheurs ont mené une étude qualitative auprès de groupes de travail composés de médecins de Montréal (au Québec), de Calgary (en Alberta) et de Toronto (en Ontario). Ils ont organisé des séances de groupes de travail avec des médecins de famille et des gastroentérologues, qui sont les médecins responsables d'aiguiller les patients vers la coloscopie de dépistage et de l'exécuter, respectivement. Ils ont préparé des guides d'entrevue pour mieux comprendre les pratiques des médecins en matière de clinique et de facturation. Ils ont filmé les discussions, les ont transcrites textuellement et les ont analysées conformément à la démarche comparative constante.

RÉSULTATS : Quarante médecins de famille et sept gastroentérologues ont participé à cinq séances de groupes de travail. Les variables relatives aux patients incluant les données démographiques (âge) et les antécédents médicaux (facteurs de risque et symptômes de cancer colorectal, facteurs risque et symptômes des médicaments contre le cancer colorectal, troubles gastrointestinaux, maladie grave). Les variables relatives à la pratique clinique incluaient le moment d'exécution de la coloscopie (soirs, fins de semaine, pendant une hospitalisation, consultation avec l'endoscopiste et coloscopie le jour même), le recours aux services (hospitalisation, examen annuel, transfert d'un autre établissement) et le profil d'utilisation de l'intervention (intervention dans le gros intestin ou autre intervention médicale ou chirurgicale avant et après la coloscopie). Cependant, l'importante variabilité des pratiques en matière de clinique et de facturation empêcheront probablement la réalisation d'un algorithme raisonnablement précis des coloscopies de dépistage. Les médecins ont proposé d'ajouter un code de coloscopie de dépistage aux données administratives sur la santé.

CONCLUSIONS : Si on ne tient pas compte des limites des bases de données administratives de santé pour déterminer les coloscopies de dépistage, on risque de tirer des conclusions erronées et d'adopter des politiques de santé inopportunes.

for conducting epidemiological and health services research on screening colonoscopy. Information on screening colonoscopy gained from administrative data could be used to measure uptake of screening, to assess resource utilization and to estimate cost effectiveness. In addition, it could be used for quality assurance because benchmarks for adenoma detection rate are defined for screening colonoscopy (3), and

${ }^{1}$ Department of Medicine, McGill University Health Centre, Montreal Quebec; ${ }^{2}$ University of Calgary, Calgary, Alberta; ${ }^{3}$ Cancer Care Ontario;

${ }^{4}$ Sunnybrook Health Centre, Toronto, Ontario

Correspondence: Dr Maida J Sewitch, Department of Medicine, McGill University Health Centre, 687 Pine Avenue West, V-Building, Montreal,

Quebec H3A 1A1. Telephone 514-934-1934, e-mail maida.sewitch@mcgill.ca

Received for publication April 5, 2012. Accepted April 24, 2012 


\section{TABLE 1}

\section{Physician focus group questions}

1. Tell me about your thoughts regarding variables that could potentially be helpful in categorizing a colonoscopy as screening or nonscreening?

2. What medications would help to categorize a colonoscopy as screening or nonscreening?

3. What are the patient characteristics that would help to categorize a colonoscopy as screening or nonscreening?

4. Please refer to the variable list that is in the folder:

a. What patient demographic and clinical information contained in the RAMQ database would be pertinent?*

b. What data from the hospital discharge database would be pertinent?

5. Are there data on physician services that could help categorize a colonoscopy as screening or nonscreening?

a. What services would be helpful to indicate a screening colonoscopy?

b. How do you feel about using timing between services to help identify screening colonoscopy?

*For Quebec. RAMQ Régie de l'assurance maladie du Québec

recommendations for wait times depend on the indication (4). Current research in colonoscopy services using administrative data is limited by the inability to account for colonoscopy indication $(5,6)-$ an important covariate for such research. Presently, there is no simple way to discern screening from nonscreening colonoscopy in these databases.

Validation studies conducted to date have been unsuccessful at developing a reasonably accurate screening colonoscopy algorithm for use in administrative health databases, with measures of accuracy ranging between $70.1 \%$ and $84 \%$ for sensitivity, and between $72 \%$ and $76 \%$ for specificity (7-9). Using the health administrative databases of the Department of Veteran's Affairs (USA), El-Serag et al (7) attempted to identify screening, surveillance and diagnostic colonoscopy. Screening colonoscopy was defined as the absence of conditions associated with diagnostic or surveillance indications and colonoscopy in the past four years. Compared with screening colonoscopy reported in the medical record, sensitivity and specificity were approximately $70 \%$. Fisher et al (8) attempted to improve on the El-Serag algorithm by using International Classification of Diseases, Ninth Revision and current procedural terminology codes. However, none of the three algorithms tested achieved more than $80 \%$ sensitivity and specificity simultaneously. Haque et al (9) used gastrointestinal diagnostic and endoscopy codes to develop an automated data algorithm to distinguish between diagnostic and screening endoscopy. Although the sensitivity was high for screening endoscopy, the algorithm ignored many diagnostic endoscopies, implying that the screening rate would be overestimated if indication was not considered. A better database algorithm is needed to distinguish between screening and nonscreening colonoscopy, which may also be useful to assess the appropriateness and effectiveness of colonoscopy utilization.

The universal access, publicly funded health care systems in the Canadian provinces provide an unparalleled opportunity to conduct population-based screening colonoscopy research using the provincial administrative health databases. These databases are used for remuneration purposes and reflect actual clinical practice. We undertook the present study to increase our understanding of the provincial administrative health data that might help to discern screening and nonscreening colonoscopy. We sought the perspectives of the physicians most involved in screening colonoscopy: the family physicians (FPs), who account for the majority of referrals to, and the gastroenterologists (GIs), who perform the majority of screening colonoscopies.

\section{METHODS}

The present triprovincial qualitative study was conducted to improve the understanding of the administrative health data that could facilitate epidemiological and health services research on screening colonoscopy. The qualitative method selected was focus groups to
TABLE 2

Focus group participants according to city and specialty

\begin{tabular}{lccc}
\hline & \multicolumn{3}{c}{ City, province, $\mathbf{n}$} \\
\cline { 2 - 4 } Specialty & $\begin{array}{c}\text { Montreal, } \\
\text { Quebec }\end{array}$ & $\begin{array}{c}\text { Calgary, } \\
\text { Alberta }\end{array}$ & $\begin{array}{c}\text { Toronto, } \\
\text { Ontario }\end{array}$ \\
\hline Primary care & 5 & 30 & 5 \\
Gastroenterology & 4 & 0 & 3 \\
\hline
\end{tabular}

obtain rich data from the exchange of ideas among participants and understand contradictions. Physician focus groups were conducted in Quebec, Alberta and Ontario to account for possible geographical variation in physician practice. A phenomenology approach was taken to understand the experiences of the physicians most involved in screening colonoscopy. Purposeful sampling was used to select FPs and GIs with experience in making referrals to and performing screening colonoscopy, and to obtain representation from English and French physicians. Discipline-specific focus group sessions were held to permit physicians to discuss their practice behaviours more openly, and thereby identify a wider range of pertinent variables, compared with mixed specialty focus groups. Focus group facilitators in each city were given the interview guide created specifically for the present study (Table 1), with the requirement that an administrator introduce the topic and questions and guide the discussion. Facilitators instructed participants to consider variables in the provincial administrative health database either alone or in groupings that could identify a screening or nonscreening colonoscopy. Field notes taken by one study investigator helped to contextualize the discussions.

Focus group discussions were audiotaped, transcribed verbatim and analyzed using the constant comparative method. Transcripts were read and assigned initial categories and codes by the focus group facilitator and one study investigator; these categories were then compared within and across transcripts. Similar themes were noted across interviews and compared, and additional codes for newly emerging topics were created as needed.

Before study inception, ethics approval was obtained from the McGill University Faculty of Medicine Institutional Review Board and local research ethics boards in Montreal (Quebec), the University of Calgary Faculty of Medicine in Calgary (Alberta), and Sunnybrook Health Sciences Centre, Trillium Health Centre and Southlake Regional Health Centre in Toronto (Ontario). Physicians provided written informed consent before participation. The present study was part of a larger study in which the objective was to develop and validate a database screening colonoscopy algorithm.

\section{RESULTS}

Five physician focus group sessions (40 FPs, seven GIs) were held in Montreal, Toronto and Calgary (May to August 2006) (Table 2). In Montreal and Toronto, two focus groups were convened according to specialty. In Calgary, one focus group was held among FPs.

Physician perceptions targeted two major categories of variables: patient- and clinical practice-specific (Table 3). Two themes were revealed regarding the patient-specific variables: demographics and medical history. All participants mentioned the importance of patient age: for screening colonoscopy, the age range was 40 to 70 years, and for nonscreening colonoscopy, the age range was $<50$ and $>85$ years.

...probably not screening if younger than 50 years. (Montreal GI)

You can't send everybody. Sometimes I send people for screening but they're usually younger, say less than 70 or 75 . I don't recommend screening colonoscopy if the patient has been through a lot lately, if they have trouble getting around, have trouble with their meds. It's too much. (Toronto FP)

Certainly in my practice, as colonoscopy has become less available, the age at colonoscopy has gone up. (Calgary FP) 
TABLE 3

Clinical and health care delivery system variables contained in administrative health databases perceived by physicians to indicate screening and nonscreening colonoscopy

\section{Screening \\ Patient variables \\ Age 40 to 70 years \\ Medical history \\ - Absence of diagnostic codes}

\title{
Nonscreening
}

Age $<50$ or $>85$ years

Medical history

- GI disease: colorectal cancer, proctorrhagia, hemorrhoids, other GI code

- Colorectal cancer risk factors: polyps, Crohn disease, ulcerative colitis

- Colorectal cancer symptoms: rectal bleeding, anemia, diarrhea, constipation, abdominal pain, weight loss

- Severe disease: congestive heart failure, chronic obstructive pulmonary disease, respiratory failure, hemiplegia, cerebrovascular arteriosclerosis, dementia, Alzheimer's disease, acute myocardial infarction, stroke, kidney failure

- Medication: for colorectal cancer risk factors, symptoms

\author{
Clincal practice variables \\ Timing \\ - Wait time to colonoscopy \\ - Same-date endoscopist consult and colonoscopy \\ Service \\ - Only one specialist visit \\ - Family physician visit following colonoscopy \\ - History of annual physical examination \\ - Absence of physician billing claim codes except for one \\ V.70 code in previous year \\ Procedure \\ - Large bowel procedure before colonoscopy \\ - Negative fecal occult blood test in the previous two years* \\ - Fecal occult blood test simultaneous with colonoscopy*
}

Timing

- Wait time to colonoscopy

- Colonoscopy occurs during hospitalization, weekend, evening, holiday

Service

- More than one hospitalization within past two years

- Transfer from chronic care, prison

- Colonoscopy performed by surgeon

Procedure

- Large bowel procedure before colonoscopy

- Positive fecal occult blood test in the past year*

- Bowel surgery, other invasive procedure simultaneous with colonoscopy

*Fecal occult blood test not available in provincial health database. GI Gastrointestinal; V.70 Routine general examination once per year

Medical history included diagnoses and medication pertinent to CRC risk factors and symptoms, gastrointestinal disorders and serious diseases, any of which would imply a nonscreening indication. Nonscreening diagnoses included, for example, inflammatory bowel disease, which is a risk factor for the development of CRC; rectal bleeding, weight loss, anemia, constipation or diarrhea, which are symptoms of CRC; gastrointestinal disorders such as hemorrhoids and proctorrhagia; and severe diseases such as Alzeheimer's disease, kidney failure and congestive heart failure, in which the benefits of colonoscopic screening may be of limited value. Discussions focused on serious medical conditions for which screening colonoscopy would not be advised.

Patients with severe congestive heart failure, chronic obstructive pulmonary disease with history of respiratory failure, hemiplegia due to carotid/cerebrovascular arteriosclerosis, dementia or Alzheimer's would not be recommended for screening colonoscopy. Patients with acute myocardial infarction would not be recommended for screening colonoscopy until a minimum of six months, or more, have passed since the acute MI. ... with complications of diabetes, dialysis patients, recent invasive malignancy (noncolorectal) without current suspicion of residual cancer, quadriplegics, paraplegics, and patients with multiple sclerosis could be recommended for screening colonoscopy. (Toronto GI)

Problems that imply urgency ... will not be screening exams.... if the patient has coronary problems, severe pulmonary problems, cirrhosis, impaired renal function, cardiac failure, pulmonary insufficiency... (Montreal GI)

In contrast, the absence of diagnostic and other physician billing claims codes might indicate a healthy individual, but certainty was not assured.

What I would say is if I have put a diagnostic code of Crohn's disease or ulcerative colitis or colon malignancy, they probably have it. If I haven't put those codes, it doesn't mean that they don't. (Calgary FP)

The absence of pertinent diagnostic codes could occur whether one or multiple diagnostic codes could be entered on physician billing claims forms because the codes themselves may be inaccurate.

And the question you raise is how useful would those diagnostic codes be? How accurate do you think your own diagnostic coding is when you submit a claim? (Calgary FP)

...you might have a patient come in and say that a next door neighbour was just diagnosed with colon cancer and they are worried that they have it. I might be just as likely to code it as anxiety. (Calgary FP)

Yearly physical exams are unlikely to produce a GI (gastrointestinal) code for screening colonoscopy. In fact, the code V.70 (routine general examination once a year) could indicate a screening colonoscopy. (Calgary FP)

I think with your complete physical, which is the one that usually generates your screening colonoscopy... I think if you have billed a GI (gastrointestinal) code of any kind, it is unlikely to be a screening colonoscopy. (Calgary FP)

Medication related to either CRC risk factors or symptoms would indicate nonscreening colonoscopy, including 5-aminosalicylic acid and iron supplements that are used to treat inflammatory bowel disease and anemia, respectively. However, physicians debated the usefulness of medication to help to differentiate screening and nonscreening colonoscopy.

...patients on iron....it could be for bleeding. Medications could be for other indications and not necessarily related to colon-related concerns. (Montreal FP) 
Clinical practice was the second category of data believed to be helpful in classifying the colonoscopy indication. Three themes emerged that related to timing of the colonoscopy, use of services and procedure use patterns. Within the timing theme, the calendar date of the colonoscopy could be helpful to identify a nonscreening indication if colonoscopy occurred during hospitalization, on a holiday, weekend or evening.

patients that are hospitalized - it's not screening... (colonoscopy) on holidays, weekends, evenings are also not screening. (Montreal GI)

Wait time to colonoscopy, measured as the number of days between the dates of the primary care/endoscopist consultation visit and the colonoscopy, would indicate a screening procedure if it were same day, while a wait time of between three months and two years could indicate either screening or nonscreening. Such wide variability in wait times was expressed among physicians within the same focus group and across provinces that even the physicians themselves questioned the utility of wait time to discerning the colonoscopy indication.

...if you have a question mark about the patient and they have had rectal bleeding, for example, then you would hope that the colonoscopy would be done within three or four weeks... whereas for screening it would be three or four months... but I don't know if there would be a strong cutoff that actually could say (that if) after three months six months from the FP visit, it's more likely to be a screening. (Montreal FP)

So if there is a colonoscopy shortly after an annual exam, that is less likely to be screening...unless the referral was made at the time of the patient's previous annual exam a year or so ago.

(Calgary FP)

Use of services such as repeat hospitalization within the previous two years of the colonoscopy date and having a surgeon perform the colonoscopy were believed to indicate a nonscreening colonoscopy. Referral from other facilities could imply either nonscreening or screening colonoscopy.

Patients transferred for first time colonoscopy from chronic care or prisons are almost always symptomatic, whereas patients transferred from nursing homes might be for either screening or diagnosis of symptoms. (Toronto FP)

Procedure use patterns were discussed as being helpful in discerning the colonoscopy indication. Procedures that were unrelated to gastrointestinal disorders that occurred simultaneously with the colonoscopy, such as biopsy (other than colon or rectal) or another investigation (other than polypectomy), were likely to infer a nonscreening indication, emphasizing that patients with active medical problems are unlikely to undergo screening colonoscopy. A nonscreening indication was also likely if the patient had undergone previous bowel surgery or polypectomy. However, procedures that were related to gastrointestinal disorders that occurred before the colonoscopy, such as sigmoidoscopy, barium enema and FOBT, were indeterminable because the long wait time to screening colonoscopy could result in use of multiple CRC screening examinations.

Sigmoidoscopy followed by a colonoscopy [indicates] someone saw something and then sent them for a colonoscopy.

(Calgary FP)

If we do a colonoscopy (within 6 months) it's because they found something in the barium enema... they saw something, they saw polyps, they saw colitis. (Montreal GI)

You know, it's not easy to get a colonoscopy appointment. I always do a barium enema first... Then I call them, and say look, I've done everything I can, please schedule my patient for colonoscopy. (Toronto FP)

...it can take a couple of years to get one (screening colonoscopy). So the consult says, 'I would like to send this person for a screening colonoscopy, but in the meantime I have ordered an FOBT'. (Calgary FP)

The absence of large bowel procedures in the year before the index colonoscopy would imply a screening colonoscopy.

...but there might be an interval where nothing else happens, so if you've got a billing code that says major complete (exam) with no other action and no other billing code in between and then you have a colonoscopy, that would indicate that it is more likely to be a screening colonoscopy. (Montreal FP)

Another area of uncertainty regarding the colonoscopy indication was the inability to capture pertinent information owing to unique coding practices on the physician billing claims forms.

...the last patient I had for a screening colonoscopy... what I wrote down on the billing claim had nothing to do with the colonoscopy because the major diagnosis was hypertension. He also was 50 and had a family history so I performed the colonoscopy... (Montreal FP)

Even if you had a code for screening then it would not be used all the time because if we find a polyp then we would not use that screening code, we would use the polyp code... (Montreal GI)

As discussions progressed, physicians recognized that many variables could imply both screening and nonscreening indications, and suggested that a screening colonoscopy code be added to the administrative health data.

...there might be the question of why aren't there two variables - one for clinical (screening) colonoscopy and the other for diagnostic colonoscopy, like there are two kinds of mammograms... (Montreal FP)

...it would be easier to have a code (for screening colonoscopy). (Montreal GI)

\section{DISCUSSION}

Physicians described widely varying clinical and billing practices that may jeopardize the accuracy of a database screening colonoscopy algorithm. Many variables were mentioned by physicians in all cities; however, differences emerged in the details and likely reflected the realities of local practices and resource availabilities. Patient age for screening colonoscopy changed depending on the city: 50 years of age in Montreal; 40 to 60 years of age in Calgary; and $<75$ years of age in Toronto. Short wait time to colonoscopy was considered to be three to four weeks in Montreal and less than two years in Calgary, while long wait time was considered to be one to two years in Toronto. Nevertheless, wait time other than same day wait time would not be helpful to discern screening colonoscopy because a screening colonoscopy that is scheduled more than one year from the consultation visit could appear as occurring shortly after the following year's annual FP visit. For other variables, there were no differences according to city, perhaps owing to the lack of specific details. Having a severe disease code 'around' the time of the colonoscopy may indicate its urgency, but specific details were missing on the number of days; likewise, for procedures that occur 'simultaneously' with the colonoscopy. Even the pattern of large bowel procedural use with colonoscopy being the last used would not necessarily indicate a nonscreening examination because some physicians use these procedures to reduce patient anxiety while waiting for a screening colonoscopy. FOBT results were believed to contribute to the colonoscopy indication; however, these data are not contained in the administrative health datasets. Finally, physician billing code practices that ignore information pertinent to the screening colonoscopy would also threaten the accuracy of a database algorithm for screening colonoscopy.

In recent years, screening colonoscopy codes have been introduced in all three provinces in which the study was conducted. These codes 
may be helpful in distinguishing between screening and nonscreening colonoscopies, but they rely on physician use patterns. Assessment of the accuracy of these codes needs to be conducted before they can be used for research.

Study limitations and strengths are considered in interpreting our findings. The long wait time to colonoscopy in Calgary was based solely on FP perceptions because there was no GI focus group. Reported wait time in Ontario and Alberta was longer compared with Quebec, which was surprising considering that both provinces had recently launched CRC screening programs $(10,11)$. Physicians from three provinces were included to enhance generalizability of our findings to other geographical locations. Perspectives were sought of the physicians who refer to and perform screening colonoscopy to better understand clinical and billing practices. We emphasize that physicians were not optimistic about the possibility of developing a reasonably accurate screening colonoscopy algorithm and suggested the addition of a screening colonoscopy code to the administrative health databases similar to what was implemented in Quebec for screening mammography. Failure to recognize these limitations by researchers and knowledge users may lead to the establishment of inappropriate health care policies.

\section{REFERENCES}

1. Leddin D, Enns R, Hilsden R, et al. Canadian Association of Gastroenterology position statement on screening individuals at average risk for developing colorectal cancer: 2010 . Can J Gastroenterol 2010;24:705-14.

2. Telford JJ. Canadian guidelines for colorectal cancer screening. Can J Gastroenterol 2011;25:479-81.

3. Rex DK, Petrini JL, Baron TH, et al. Quality indicators for colonoscopy. Am J Gastroenterol 2006;101:873-85.

4. Paterson WG, Depew WT, Pare P, et al. Canadian consensus on medically acceptable wait times for digestive health care. Can J Gastroenterol 2006;20:411-23.

5. Rabeneck L, Paszat LF, Saskin R. Endoscopist specialty is associated with incident colorectal cancer after a negative colonoscopy. Clin Gastroenterol Hepatol 2010;8:275-9.

6. Baxter NN, Sutradhar R, Forbes SS, Paszat LF, Saskin R, Rabeneck L. Analysis of administrative data finds endoscopist quality measures associated with postcolonoscopy colorectal cancer.

Gastroenterology 2011;140:65-72.

\section{CONCLUSION}

Variability in physician clinical and billing practices may contribute to the inability to develop a reasonably accurate database screening colonoscopy algorithm. Researchers and decision makers need to be aware that administrative health databases should not be used for discerning screening colonoscopy and that failure to recognize this limitation may lead to incorrect conclusions that influence health policy. Given the perspectives expressed in the present study and the unsuccessful attempts to develop a screening colonoscopy algorithm, the addition of a screening colonoscopy code may enhance the usability of the administrative health data for research purposes in Canada and elsewhere.

ACKNOWLEDGEMENTS: This research was supported by an operating grant from the Canadian Cancer Society. At the time this study was conducted, Maida J Sewitch PhD was supported as a Research Scientist of the Canadian Cancer Society; she is now supported as a Research Scholar of the Fonds de recherche du Québec - Santé.

7. El-Serag HB, Petersen L, Hampel H, Richardson P, Cooper G. The use of screening colonoscopy for patients cared for by the

Department of Veterans Affairs. Arch Intern Med 2006;166:2202-8.

8. Fisher DA, Grubber JM, Castor JM, Coffman CJ. Ascertainment of colonoscopy indication using administrative data. Dig Dis Sci 2010;55:1721-5.

9. Haque R, Chiu V, Mehta KR, Geiger AM. An automated data algorithm to distinguish screening and diagnostic colorectal cancer endoscopy exams. J Natl Cancer Inst Monographs 2005;35:116-8.

10. The Alberta Cancer Board and Foundation. Alberta Colorectal Cancer Screening Program. <www cancerboard ab ca/PS/Screening/ Colorectal/2008> (Accessed January 13, 2009).

11. Ministry of Health and Long-Term Care. Ontario's Colorectal Cancer Screening Program. <www.cancercare.on.ca/english/home/ pcs/screening/coloscreening/cccworks/2008 (Accessed January 13, 2009). 


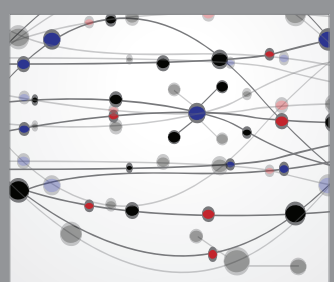

The Scientific World Journal
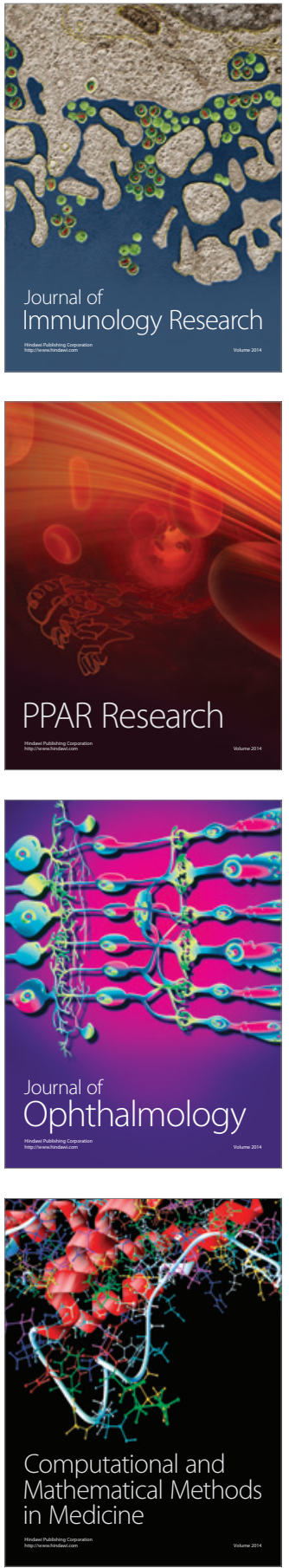

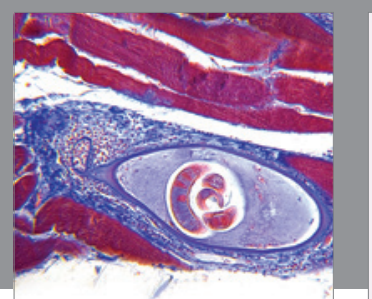

Gastroenterology Research and Practice

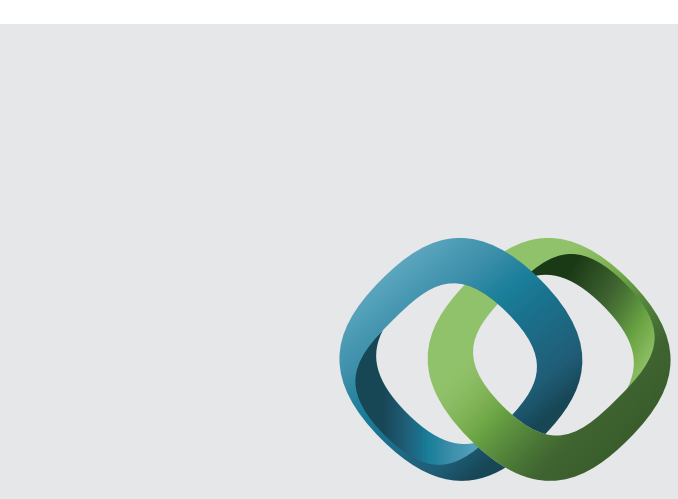

\section{Hindawi}

Submit your manuscripts at

http://www.hindawi.com
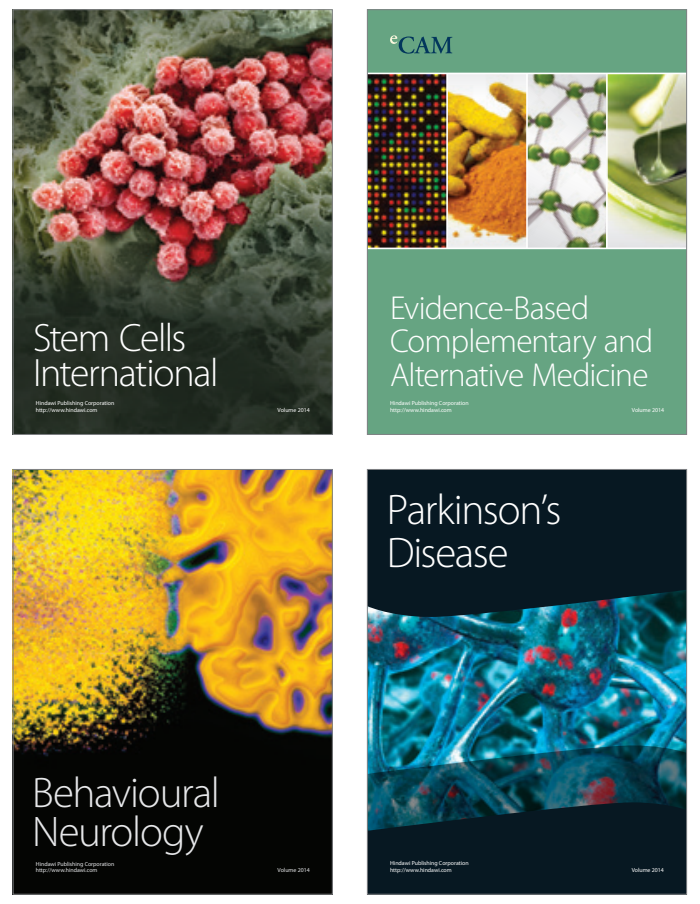
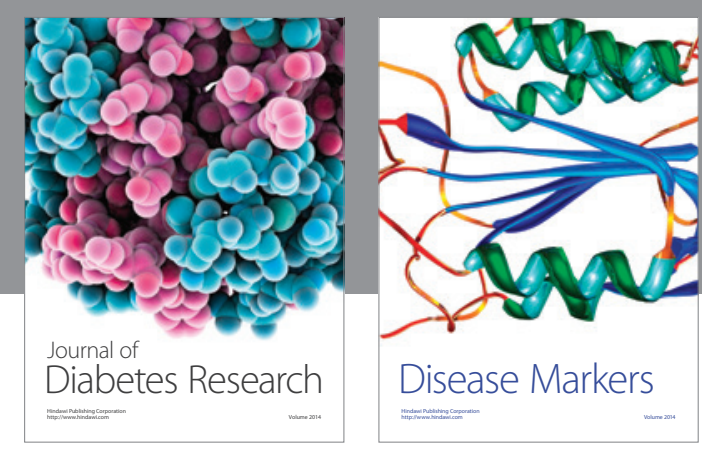

Disease Markers
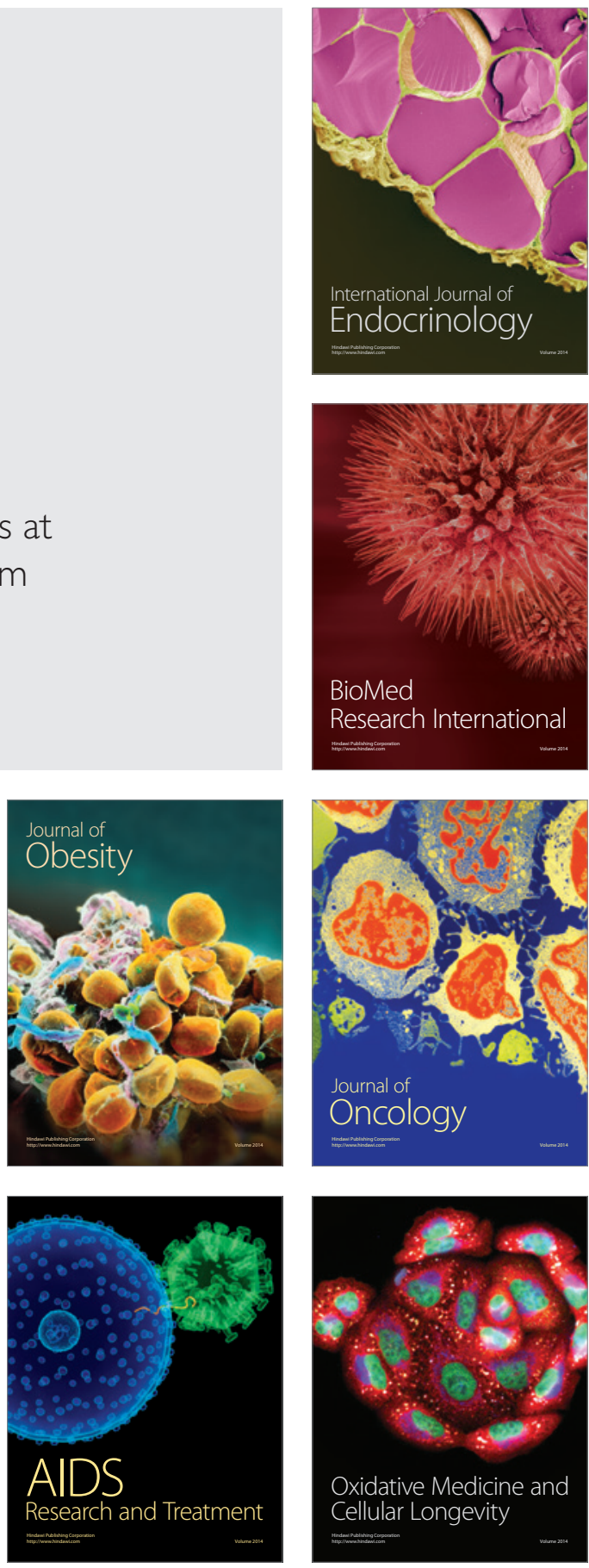